\title{
Influences of the Air in Metal Powder High Velocity Compaction
}

\author{
Jun Liu,Haifeng $\mathrm{Hu}$ and Xiaolong Luo \\ Faculty of Mechanical Engineering \& Mechanics, Ningbo University, Ningbo 315211, China
}

\begin{abstract}
During the process of metal powder high velocity impact compaction, the air is compressed sharply and portion remains in the compacts. In order to study the Influences, a discrete density volleyball accumulation model for aluminium powder was established with the use of ABAQUS. Study found that the powder porosity air obstruct the pressing process because remaining air reduced strength and density of the compacts in the current high-speed pressing $(\mathrm{V} \leqslant 100 \mathrm{~m} / \mathrm{s})$. When speed further increased $(\mathrm{V} \geqslant 100 \mathrm{~m} / \mathrm{s})$, the temperature of the air increased sharply, and was even much higher than the melting point of the material. When aluminium powder was compressed at a speed of $200 \mathrm{~m} / \mathrm{s}$, temperatures of air could reach $2033 \mathrm{~K}$, far higher than the melting point of $877 \mathrm{~K}$. Increased density of powders was a result of local softening and even melt adhesive while air between particles with high temperature and pressure flowed past.
\end{abstract}

\section{Introduction}

Powder metallurgy is a near net shape technology which has a huge advantage on some materials difficult to produce in the traditional way [1]. Powder dynamic repression has been carried out for decades, and pressing speed of 200 meters per second or more, the weight of the hammer also ranged from a few grams to several tons.

During the process of HVC (High velocity impact compaction), speed not only affects friction state and hardening of powder, but also affects the air to escape from the powder particles gap. In the study of high speed pressing, many scholars consider that the increased density is a result of excluding air in powder after several times of suppression. Wang Jianzhong [2] thinks the density should be higher due to less air remaining after holding pressure in the process of HIP (Hot Isostatic Pressing ). However, some found that air pressure in compacts was lower than the compacting pressure within two orders of magnitude in the process of HVC [3]. Chen Jin [4] found density was lower through experiments which the powder was performed high-speed suppression after pre-pressed. Ma Binbin ${ }^{[5]}$ considered in certain pressing speed and the friction coefficient, powder compaction and sintering of synchronization are achievable for most metal powder.

ABAQUS is one of the most advanced finite element analysis software in the world [6]. Liquid-solid coupling approach was used was used to simulate high-speed aluminium powder pressing process by ABAQUS, and air escaping mode was analysis and discuss the impact of air during the process.

\section{Model and parameter settings}

There are many kind of particles shape ,and mist method can get a better atomization of spherical particles ${ }^{[7]}$.For convenience, the powder particle were set as diameter disc with $100 \mu \mathrm{m}$. The model was shown in Fig 1, and the concave edge model was shown in Fig 2.The punch was on the top, and air flow field was established, then divided Euler mesh size and the die cavity Fig 3 equivalents and impart to the flow field at the aperture, so that the impact of the powder particles and air could be simultaneously analyzed at the same time besides the air was depend as an ideal air.

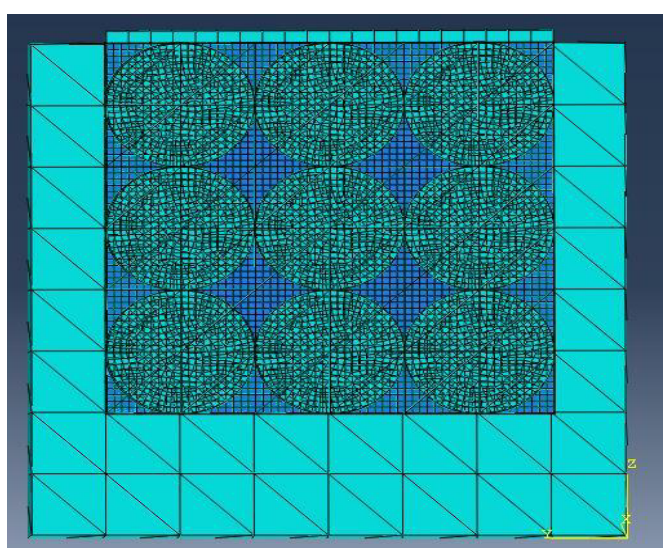

Figure 1. Powder compaction model 


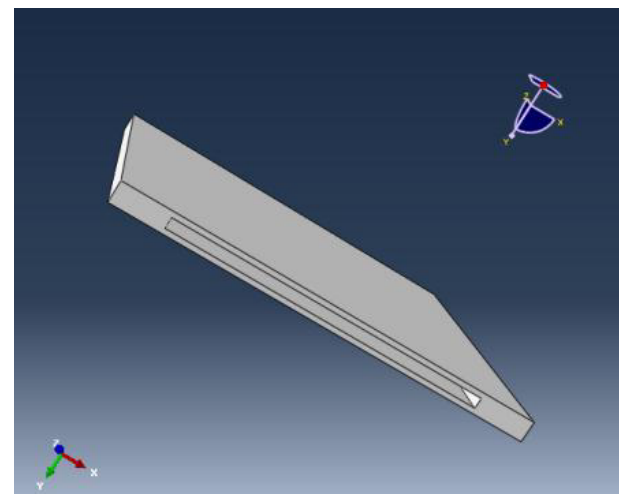

Figure 2. Powder compaction die model

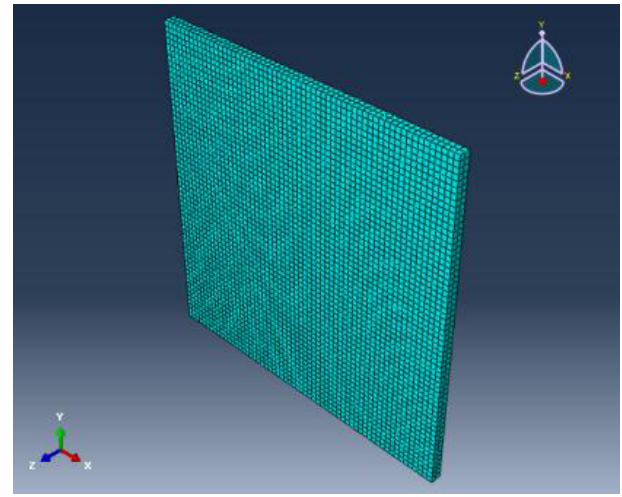

Figure 3. Air flow model of powder compacting

As a commonly kind of material with low melting point, aluminium were selected to be study .Meanwhile Johnson-Cook model can well describe the work hardening of metal materials, the strain rate effect and the softening effect as the constitutive relation of the powder particles $^{[8]}$. In its general form:

$$
\begin{gathered}
\sigma=\left(A+B \varepsilon^{n}\right) \cdot\left(1+C \ln \dot{\varepsilon}^{*}\right) \cdot\left(1-T^{*}\right) \\
\dot{ }^{*}=\frac{\dot{\varepsilon}}{\bullet} \\
\varepsilon_{0}
\end{gathered}
$$$$
T^{*}=\frac{T-T_{r}}{T_{m}-T_{r}}
$$

$\mathrm{A}$ is material in the quasi static yield strength; $\mathrm{B}$ is strain hardening modulus; $\mathrm{n}$ is strain hardening index; $\mathrm{C}$ is the strain rate sensitivity index; $\mathrm{m}$ is temperature softening coefficient; $\varepsilon$ is equivalent plastic strain; $\dot{\varepsilon}$ is strain rate; $\dot{\varepsilon}_{0}$ is the reference strain rate; $T$ is temperature material; $T_{\mathrm{r}}$ is room temperature; $T_{m}$ is melting point materials.

The process was adiabatic due to a very short period of time; Dynamic display method is adopted because the stress field and the temperature field intersect each other in powder compaction .

\section{Simulation results and analysis}

From Fig 4 to Fig 6, Compaction temperature was 298 K, and pressing speed was $10 \mathrm{~m} / \mathrm{s}$, besides round particles represents a metal powder while the white was the air. From the results, the temperature rise of the powder particles were mainly produced by plastic deformation of the particles since the friction was not defined.As a result, the temperature at the grain contacts was higher than in the center, which was correlated with the degree of deformation of the particles. And the air in the models with repression carried out by the punch. Ultimately only a small part of the air was left between the particles and the particles enclosed at the aperture.

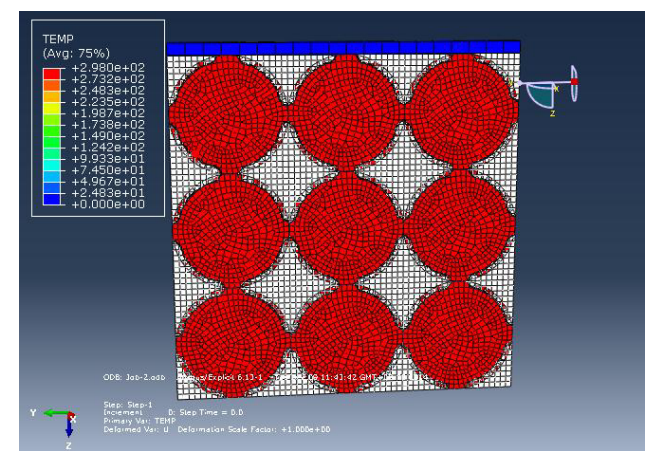

Figure 4. At $0 \mu \mathrm{s}$

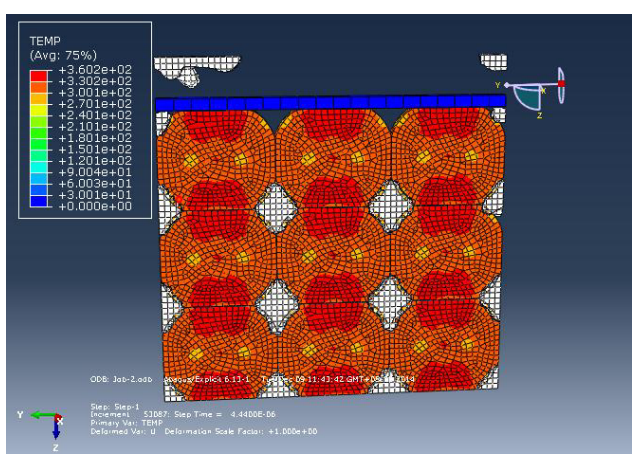

Figure 5. At $4.44 \mu \mathrm{s}$

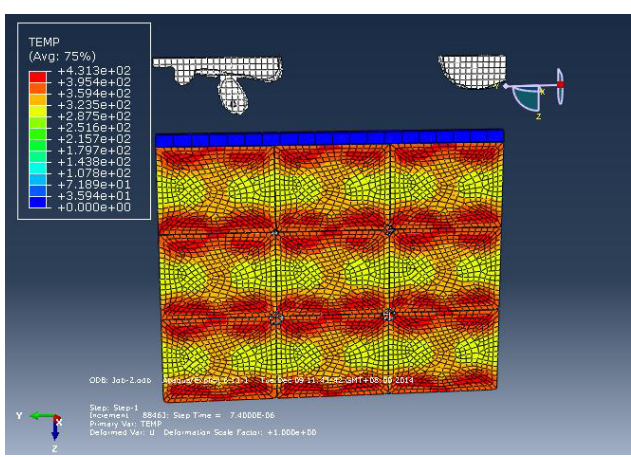

Figure 6. At $7.4 \mu \mathrm{s}$ 
The temperature rise of the air when aluminium powder was pressed at different speeds is shown from Fig 7 to Fig 10. It can be seen the temperature in the air was gradually increased with the pressing speed. At the same time, air temperature rise of inter-particle porosity contrast at $50 \mathrm{~m} / \mathrm{s}$ was not significantly to $10 \mathrm{~m} / \mathrm{s}$, and the temperature was still far below the melting point of the material even at speed of $100 \mathrm{~m} / \mathrm{s}$. Air temperature would rise sharply when the speed reaches $200 \mathrm{~m} / \mathrm{s}$, and the highest temperature reached at $2033 \mathrm{~K}$. Fig 11 is air temperature at different speeds. The air temperature increased dramatically only when the speed was more than $100 \mathrm{~m} / \mathrm{s}$. Because the air could not remain in the powders, and most of the air would escape outside the model at a rate of tens of meters per second. The air was too late to escape as a result of abruptly deformed $\mathrm{s}$ between particles when a speed more than one hundred meters per second case, and temperature rapid rise with increasing pressure to reduce the volume.

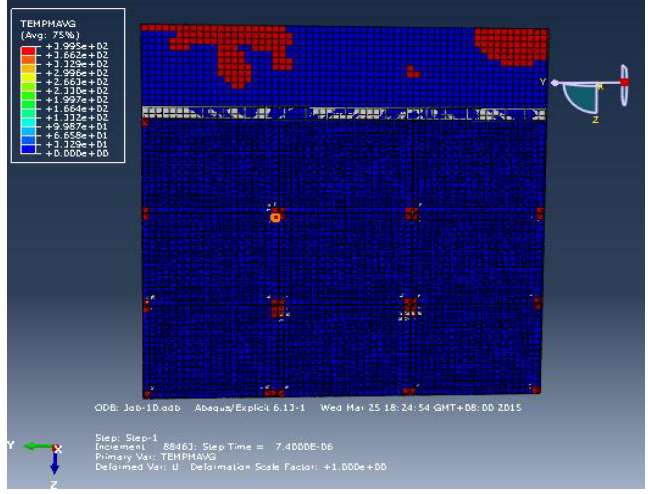

Figure 7. Temperature between the air at $10 \mathrm{~m} / \mathrm{s}$

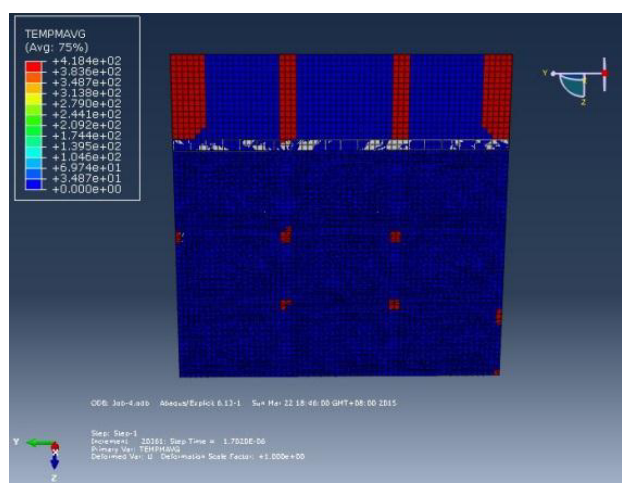

Figure 8. Temperature between the air at $\mathbf{5 0} \mathbf{~ m} / \mathbf{s}$

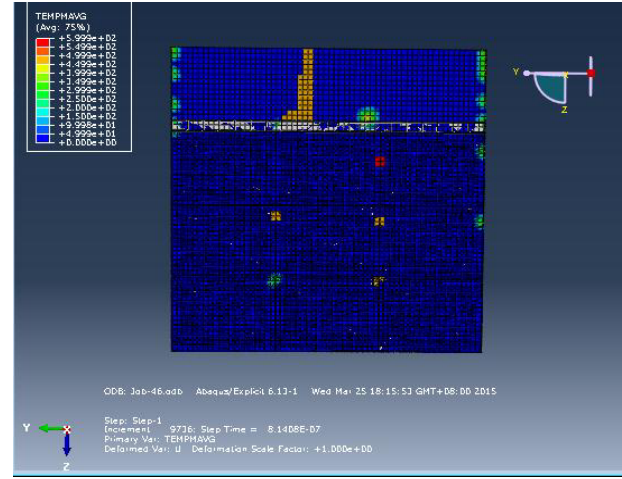

Figure 9. Temperature between the air at $\mathbf{1 0 0} \mathbf{~ m} / \mathbf{s}$

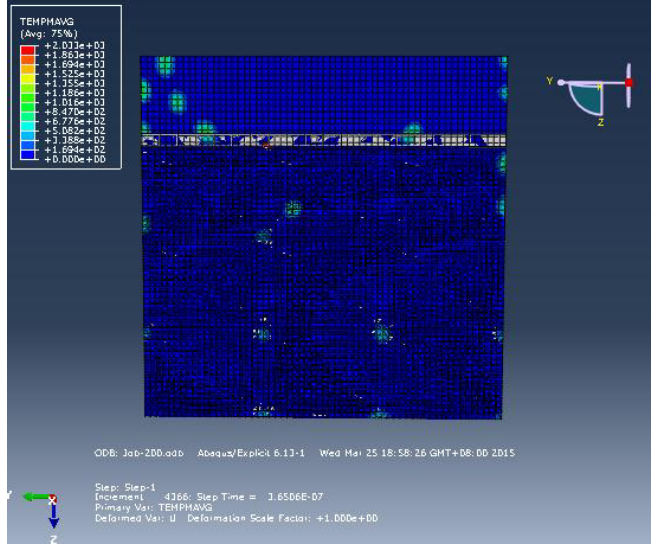

Figure 10. Temperature between the air at $200 \mathrm{~m} / \mathrm{s}$

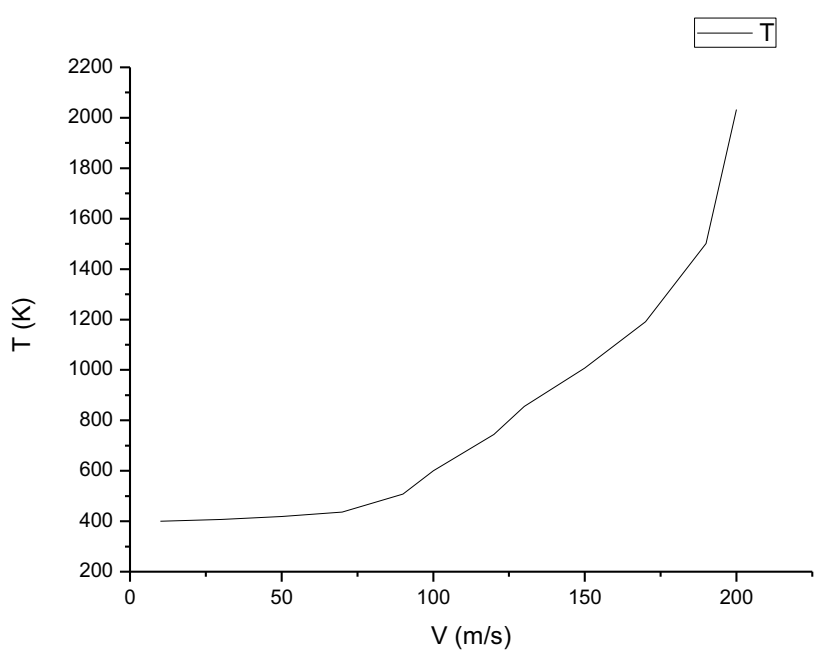

Figure 11. The maximum temperature rise of air at different speeds

The temperature rise rate of air porosity under different initial temperatures of the powder particles at $10 \mathrm{~m} / \mathrm{s}$ is shown in Fig 12 and Fig 13. Pressing temperature had little effect on the initial porosity of the temperature rise, and the final temperature was about $100 \mathrm{~K}$.

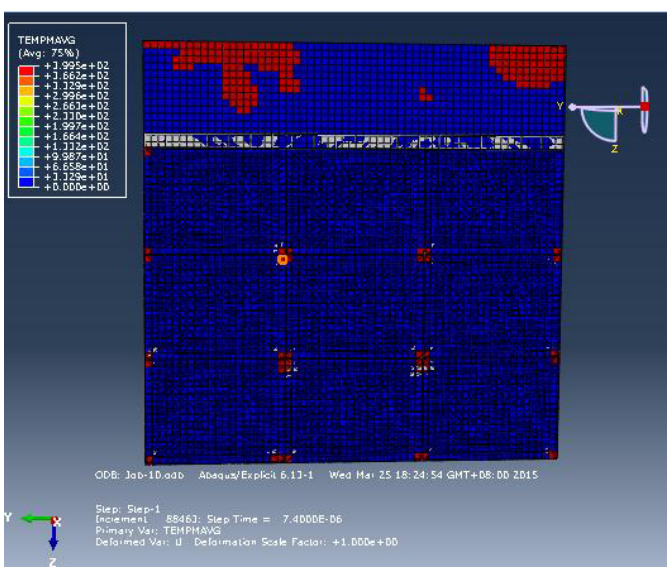

Figure 12. The temperature rise when initial temperatures of air porosity was $298 \mathrm{~K}$ 


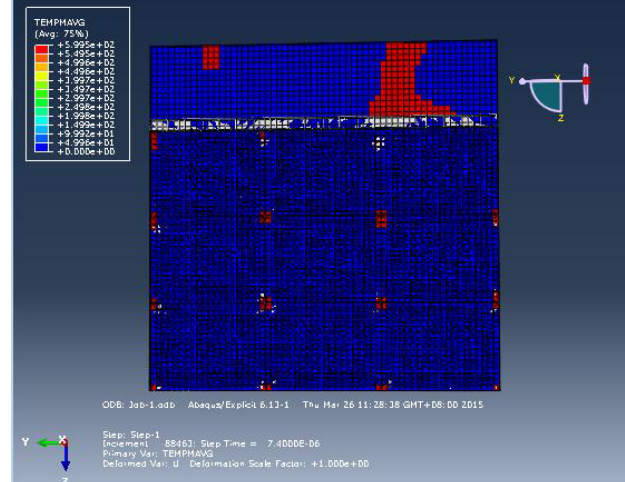

Figure 13. The temperature rise when initial temperatures of air porosity was $498 \mathrm{~K}$

As can be seen from Figure 14, air pressure finally rises again after the first and then decreased. The reason may be that the air pressure is low in the initial stage of pressing, and Pressing speed is faster than, as a result, the air pressure increases with increasing pressure. The pressure reduced with the rate of air evolution increased. As it can be seen from Fig. 15, the temperature of air rises rapidly in the initial stage, essentially stayed unchanged.

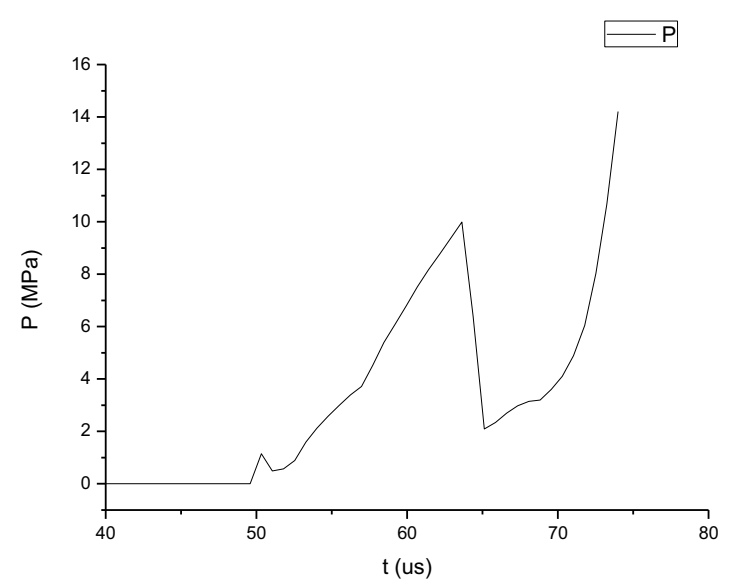

Figure 14. Pressure of air

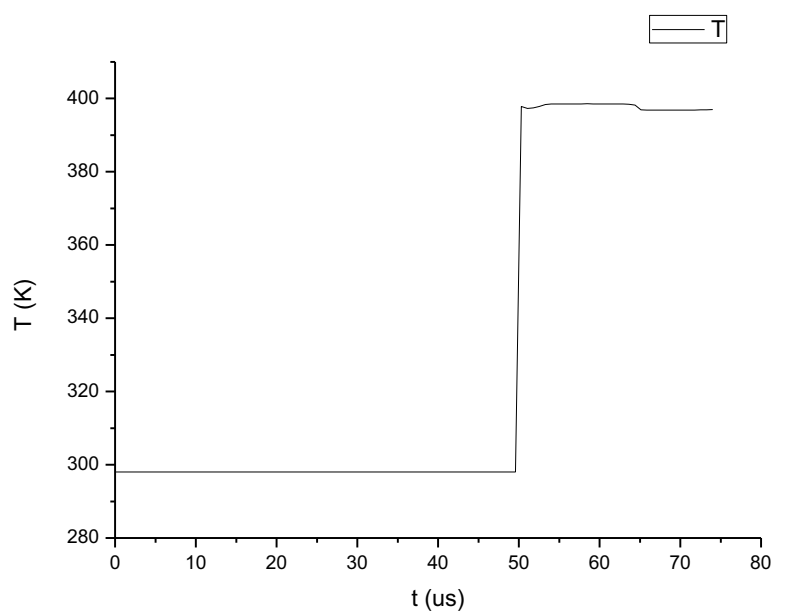

Figure 15. Temperature of air

\section{Conclusion}

(1) During the process of metal powder high velocity impact compaction, the air temperature rises with the repression though it has little effect on the consolidation of powder particles melt when pressing speed is about tens of meters per second. Meanwhile, holes would form with a fraction of the air remaining at the end. Therefore, air impedes pressing process in the common high-speed.

(2) Temperature of the air rises sharply when the pressing speed is higher than $100 \mathrm{~m} / \mathrm{s}$, and is even much higher than the melting point of the material. The surface of the adjacent powder particles would partial soften even melt adhesive as results of further increase in temperature at the interface of high-pressure powder. So air porosity plays a catalytic role during pressing.

(3) The initial temperature has no effect on the temperature rise of the air in a conventional powder pressing since a large amount of air can not remain in the powder because of low speed.

\section{Acknowledgements}

This research was financially supported by National Natural Science Foundation of China (No. 11372148).

\section{References}

1. Qu X H, Yi H Q. Materials China .J. 29, 45-49(2010).

2. Wang J Z. Research on densification mechanism of powder high velocity compaction (Doctoral dissertation). Beijing:University of Science and Technology Beijing,2009.

3. Sano Y, Miyagi K. Int. J. Powder Metall. Powder Technol.J.20,115-118 (1984).

4. Chen J. Investigation on equipment development and densification mechanism of warm powder high velocity compaction (Doctoral dissertation). Guang zhou:South China University of Technology,2011.

5. Ma B B,Hu X P,Liu J.Hot Working Technology .J.01 91-95(2016)

6. Shi Y P, Zhou Y R.ABAQUS Finite Element Analysis [M] .Beijing: China Machine Press,2006.

7. Sun L. Mesoscopic simulation on the compression deformation process of powder particles(Doctoral dissertation). Hefei: Hefei University of Technology (2013)

8. Johnson.G.R, Cook. W.H. A constitutive model and data for metals subjected to large strains, high strain rates and high temperatures[C]//7th International Symposium on Ballistics. The Netherlands: Hague, 1983. 541-547. 